\title{
Quality of Family Planning Services in Kersa Woreda, Jimma Zone, Southwest Ethiopia: A Facility Based Cross-Sectional Study
}

\author{
Tarekegn Jabara ${ }^{1}$, , Elias Ali ${ }^{2}$, Zalalem Kaba ${ }^{3}$ \\ ${ }^{1}$ Marie Stopes International Ethiopia, Ambo, Ethiopia \\ ${ }^{2}$ Health Science Institute of Jimma University, Jimma, Ethiopia \\ ${ }^{3}$ East Wollega Zonal Health Office, Nekemte, Ethiopia \\ Email address: \\ tarejabara@gmail.com (T. Jabara), eliasaliyesuf@yahoo.com (E. Ali), kabazalalem@gmail.com (Z. Kaba) \\ ${ }^{*}$ Corresponding author
}

\section{To cite this article:}

Tarekegn Jabara, Elias Ali, Zalalem Kaba. Quality of Family Planning Services in Kersa Woreda, Jimma Zone, Southwest Ethiopia: A Facility Based Cross-Sectional Study. American Journal of Clinical and Experimental Medicine. Vol. 9, No. 4, 2021 , pp. 86-101. doi: 10.11648/j.ajcem.20210904.12

Received: June 23, 2021; Accepted: July 14, 2021; Published: July 22, 2021

\begin{abstract}
Improving quality of care has been a necessary goal for family planning programme worldwide. The unmet need for family planning services in Ethiopia is believed to be high $(26 \%)$ while the already available services do not appear to be optimally used by potential clients. It was assessed the quality of family planning services provision. Facility based quantitative and qualitative cross-sectional study based on James Bruce analytical framework was employed from May 1-30, 2016. Three hundred one (301) family planning service users for exit interview and 40 female clients observed while taking service and 4 service providers from four health centers participated for in-depth interview. Facility audit was made on four health centers. Linear regression was used for data analysis. Based on the overall satisfaction score; $68.8 \%$ of clients were satisfied in family planning services. Having more children, currently breast feeding, discussion of family planning with husband or partner, and family size were the significant predictors of client satisfaction to family planning services. It revealed that, for a single individual increase in family size the satisfaction score decreases on average by 0.8 at $\mathrm{p}=0.007$, CI $(0.005$ $0.034)$. For a unit increase in need to have more child, client satisfaction decreases by 0.947 at $p=0.002, \mathrm{CI}(0.019,0.088)$. Utilization of information, education and communication material during consultations was low (65\%). Providers didn't assessed critical information's in more than two third of observed sessions of history taking and physical examinations. Hence, service providers should be sensitized and motivated to give complete information on a method to the client. The way family planning providers comply with guideline recommendations and utilize information, education and communication materials consistently during client consultations need to be designed by respective health centers.
\end{abstract}

Keywords: Family Planning, Quality, Kersa Woreda

\section{Introduction}

Family planning is the planning of when to have children, and the use of birth control and other techniques to implement such plans with services commonly used like sexuality education, prevention and management of sexually transmitted infections, pre-conception counseling and management, and infertility management. Family planning is choosing the number of children in a family and the length of time between their births [1]. Family planning is today considered as important in reproductive health and human rights. It is an important component of primary health care, maternal and child health. It is the means of planning families that want space according to choice and time to fit in with life decisions. Contraception is an important issue for all couples, and the method used should be decided by the women and her partner jointly. This process is facilitated by establishing a trusting relationship with the client and by providing unbiased, accurate information about all methods available [2-4]. 
The International Conference on Population and Development (ICPD) held in Cairo in 1994 recognized that reproductive health is a critical part of an individual's wellbeing and is central and critical to human development. ICPD established a paradigm shift from family planning to a more comprehensive approach of reproductive health and rights, premised on the life cycle 2 approach in which reproductive health concerns are not limited to women of reproductive age but to men and youth making quality service its central point [5].

Ethiopia showed substantial increase in the use of contraceptives in the last decade through a significant effort to scale up family planning services. The contraceptive prevalence rate increased from $8 \%$ in 2000 to $42 \%$ in 2014 among married women of reproductive age. However, about $26 \%$ of women have not yet taken any type of contraceptive despite their demand [6].

Studies in a variety of settings have identified constraints to good quality services in family planning. These include deficiencies in physical facilities and equipment; disruptions in supplies; insufficient information provided to clients; and providers' insensitivity to the feelings and needs of clients [7]

New insights show that in several developing countries fertility rates that were declining are beginning to halt. These halt in fertility decline are associated with a leveling off in contraceptive use, the demand for family planning, and the number of wanted births [8]. Contraceptive prevalence rate of Kersa Woreda is lower than the zonal average achievement. Even though health facilities coverage are almost $100 \%$ and different non-governmental organizations (NGO's) supporting the program, family planning service utilization is less than $50 \%$ for more than half of a decade [9].

Although there are previous studies conducted in the zone; 13 and 5 years back $[10,11]$; it will be expected that there will be change in the condition of the service delivery and continues change in community need. There is also a change of government strategy towards quality service but the previous studies were done in the period when government policy was towards achieving universal accessibility of service than quality issue. The objective of this study was to assess the satisfaction of family planning clients towards the services, investigate the technical competence, interpersonal relations and examine the facilities and resources useful for the provision of effective family planning services in health facilities of Kersa Woreda, Jimma Zone, South west Ethiopia

\section{Methods and Materials}

\subsection{Study Area and Period}

Kersa Woreda is one of the eighteen Woredas in Jimma zone in Oromia region, which is located in the Southwestern part of Ethiopia $330 \mathrm{~km}$ (kilometer) from Addis Ababa; the nation capital, and $22 \mathrm{~km}$ East of Jimma town (the Zone capital) on the road to Addis Ababa bounded by Tiro Afeta Woreda in the north, Jimma town in west, Omonada Woreda in the east and Dedo Woreda in southern part. The capital town of the Woreda is called Serbo. Kersa Woreda has 32 kebeles (the lowest administrative unit in Ethiopia), 2 urban and 30 rural. According to national statistical authority in 2015 the total population is estimated to be 210,489 . From this population $168,084(88.9 \%)$ are rural population, while $20,880(11.1 \%)$ are urban resident. Out of the total population 46,581 are females of reproductive age. Currently there are seven governmental health centers, thirty three health posts and seven private small clinics, which are providing health service in the Woreda. The contraceptive prevalence rate (CPR) of the Woreda is $41.7 \%$ [9]. The study was conducted from May 1 to 30, 2016.

\subsection{Study Design}

Facility based cross-sectional study using both qualitative and quantitative data collection method was conducted based on the framework of James Bruce [1990].

\subsection{Population}

\subsubsection{Source Population}

a) For exit interview:-all female FP service users in the reproductive age group who visited the service delivery points (SDPs) during the data collection period.

b) For in-depth interview:-FP service providers and SDPs in the Woreda.

\subsubsection{Study Population}

a) For exit interview:-all female FP service users in the reproductive age group who fulfill inclusion criteria and visited the SDPs during the data collection period.

b) For in-depth interview:-selected FP service providers who were in the facility at the date of data collection and sampled SDPs were included.

\subsection{Inclusion and Exclusion Criteria}

\subsubsection{Inclusion Criteria}

a) All reproductive age women using FP service during data collection period (for exit interview).

b) Head of FP service unit (for in-depth interview) were included.

\subsubsection{Exclusion Criteria}

FP users who were severely ill excluded from the study.

\subsection{Sample Size and Sampling Technique}

\subsubsection{Sample Size Determination}

a) For the quantitative part:-the required sample size was determined by using single population proportion formula considering the following assumptions:-50\% proportion of satisfied clients (to get maximum sample size), 0.05 level of significance, and margin of error (5). Non-response rate $=10 \%$, and the formula for calculating the sample size was:

$$
\mathrm{n}=\frac{(Z \alpha / 2)^{2} * p q}{d^{2}}
$$


Where; $\mathrm{n}=\mathrm{is}$ the required sample size, significance level $=0.05$,

$P=$ is the estimated proportion of satisfied clients $=50 \%$,

$\mathrm{q}=1-\mathrm{p}=0.5, Z_{\alpha / 2}=1.96$ at $95 \% \mathrm{CI}$,

$\mathrm{d}=$ is the relative margin of error tolerated $=5 \%$,

$\mathrm{n}=\frac{1.96^{2} \cdot(0.5)(0.5)}{\left(0.05^{2}\right)}=384+39$. But, since the total population under study was manageable [12] that is, 428 all clients who come for service during the study period were included.

b) For qualitative part:-4 service providers (one provider or one sampled SDP).

\subsubsection{Sampling Procedure}

Four health centers from each primary healthcare unit (PHCU) was included by purposive sampling based on its location (urban healthcenter-Serbo), the other three health centers (HCs) are selected randomly as shown below considering each health center supervises health posts (HPs) under that PHCU. If there is quality service at each HC it's expected to be disseminated at HP. Data was collected consecutively during the study period.

The observation was done on different time intervals (1 cases at morning time, 1 cases day time, 1 cases afternoon for randomly selected routine working day of the week and additional observations on special days like market days and weekend with the above mentioned time interval with total 10 observations per each HC making overall 40 observation. The schematic presentation of the sampling procedure is given in the figure 1 below.

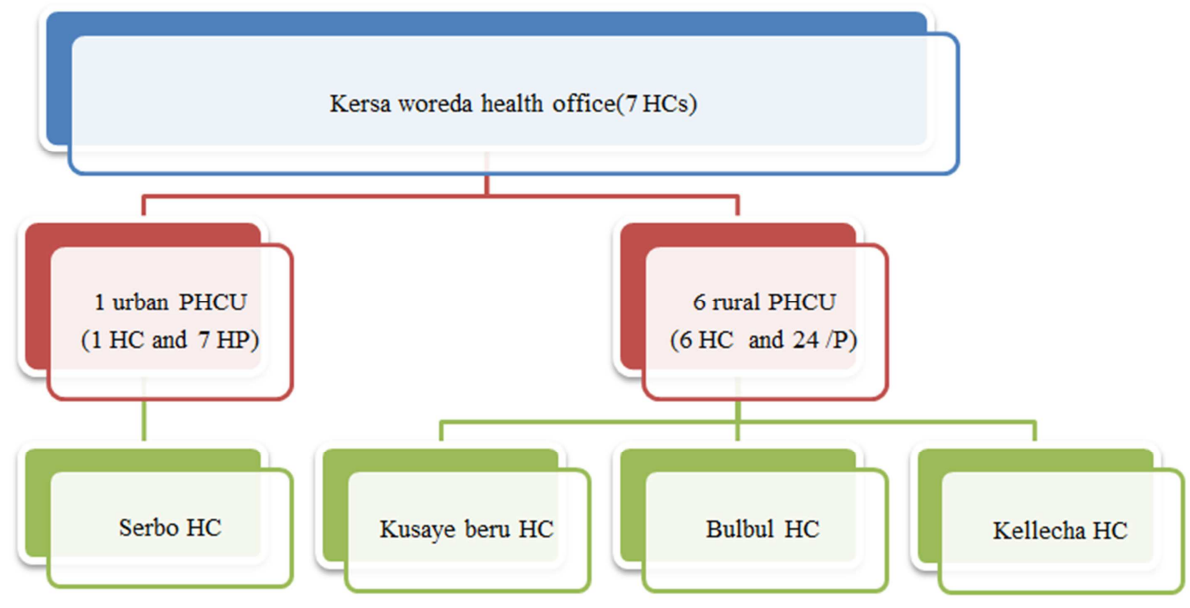

Figure 1. Schematic representation of the sampling procedure.

Table 1. Sample size for selected SDPs, Kersa Woreda public health centers, Jimma zone, Southwest Ethiopia, May 2016.

\begin{tabular}{lllll}
\hline S. no & Name of Health center & $\begin{array}{l}\text { No of client who came for service } \\
\text { during data collection }\end{array}$ & Clients who were interviewed & Clients for observation \\
\hline 1 & Serbo & 91 & 122 & 81 \\
2 & Kusaye beru & 52 & 122 & 10 \\
3 & Bulbul & 48 & 40 & 10 \\
4 & Kellecha & 313 & 301 & 10 \\
& Total & 40 \\
\hline
\end{tabular}

For In-depth interview:-Four Service providers who were FP service unit head were selected purposively.

For facility audit:-Four SDPs (Serbo, Bulbul, Kusaye beru and Kellecha HC) were studied.

\subsection{Data Collection Instruments and Procedure}

\subsubsection{Data Collection Instruments}

A pretested, structured and translated questionnaires adapted from various studies $[13,11,14]$ and modified to the local situation was used for face-to-face exit-interview. Pretest was done on non-study health center in the Woreda called Bala-wajo $\mathrm{HC}$ on (5\% of sample size) and necessary corrections were made. For observation of client provider interaction observational checklist developed based on national guideline was used. For qualitative data: semistructured in-depth interview guide was utilized. It has four parts.

a) Part one: Background information and Exit interview question on client satisfaction. It includes general information including socio-demographic characteristics of FP clients. Structured question of 13 items which was adapted was used for client exit interview. It consisted of closed-ended questions and composed of both original questions suggested by the national guideline and considered from previous studies [11, 14] that have mainly dealt about quality of care in FP.

b) Part two: structured checklists; for observation of client provider interaction based on national FP service guideline was used.

c) Part three: Semi-structured in-depth interview guide prepared based on national and WHO FP service guideline was used to conduct in-depth interview with FP service providers on their experience

d) Part four: Checklist for inventory. Availability and functionality of the system was assessed using a 
national checklist for FP service.

\subsubsection{Data Collection Procedure}

Four Diploma Nurses who are fluent Afaan Oromo speakers from non-study $\mathrm{HC}$ have conducted exit interview. For direct observation of client provider interactions two certified FP provider Nurses from non-study HCs were recruited. Forty (40) clients were observed while the service was provided at the spot. For this purpose, data collectors were provided with observational checklists to mark yes or no answers and other activities, which reflect the quality of family planning services. Since data collectors were health professionals, they have weared a white coat to blend in to the service delivery. A semi structured in-depth interview guide was also used to conduct in-depth interview with the providers by one health officer. The information was written down by the principal investigator and assistant data collector and one BSc certified FP provider was recruited as supervisor. Inventory was made on the presence and functionality of the different logistics and supplies at the service delivery points by PI and in-depth interviewer.

\subsection{The Study Variables}

Variables:
a) Client satisfaction
b) Client provider interaction
c) Provider competence
d) Availability of logistics and supplies
e) Socio demographic variables

\subsubsection{Outcome Variable}

Client satisfaction.

\subsubsection{Independent Variables}

a) Socio-demographic variables (Age, marital status, educational status, religion, occupation, residence and desire for additional children)

b) Information given to clients

c) Waiting time

d) Choice of methods

e) Availability of trained staff

\subsection{Data Analysis Procedure}

The Data was entered into an EpiData 3.1 database and exported to be analyzed with SPSS 20.0 windows statistical software applications.

Reliability and Validity Statistics

There were 13 questions on five point Likert scale with score value ranging from 1 (strongly Disagree) to 5 (strongly agree). First scale transformation was done for each item by the following formula.

$$
\mathrm{SS}(\text { satisfaction score })=\frac{\text { Actual score }- \text { Minimum score }}{\text { Maximum score-minimum score }}
$$

Cronbachs Alpha of outcome variable with 13 items $=0.63$. Items with inter item correlation coefficient $<0.3$ and each item correlation coefficient with new construct $(\mathrm{SS})<0.3$, and $\geq 0.9$ removed then Cronbachs alpha value become 0.64 . Then satisfaction score of new construct with 9 items with above criteria computed, and then data was explored and used in regression equation. Cronbachs alpha of independent variables with 18 items was 0.59 . After removing items with correlation coefficient $<0.3$, fourteen (14) items selected and Cronbachs alpha become 0.70. Linear regression analysis was used to assess the relationship between the outcome variable (computed clients satisfaction score) and the independent variables. Variables with p-value less than 0.25 on bivariate linear regression were selected for multiple linear regressions. Multiple linear regression done and significance of the findings was declared at $p<0.05$. The qualitative data was coded, categorized and analyzed thematically then presented narratively and triangulated to the quantitative findings. The result was presented using descriptive statistics including frequency tables, percentages, graphs, mean and standard deviation for variable under study.

Data Quality Assurance

Training was given for data collectors (one day theoretical and one day practical). Questionnaire that was translated to Afaan Oromo and used previously [11] was utilized after retranslation to local context. The questionnaire was pre-tested on $5 \%$ of study unit ( 21 clients) in non-study $\mathrm{HC}$ in the same Woreda before the actual data collection. Data collectors were oriented to check the completeness of each questionnaire at the end of each interview. Certified and experienced family planning service providers were used for observation of client provider interaction. The principal investigator (PI) together with coordinator has rechecked completeness of the questionnaire immediately after interview at field level and during submission. The completed questionnaire was checked for completeness, consistency and coded by the PI. Double entry of the data was made on EpiData version 3.1.

\subsection{Ethical Consideration}

Before the fieldwork, ethical clearance was obtained from IRB, Jimma University College of public health and medical sciences. Then formal letter of cooperation was written from Jimma zonal health office to Kersa Woreda health office and then to each service delivery points. Response of clients was anonymous and data collectors have informed clients that they have full right to discontinue or refuse to participate in the study. A letter of agreement was also attached to questionnaire to obtain the permission of each individual. Then observers have obtained permission from both providers and clients to be present during individual counseling and clinical examination.

\subsection{Operational Definitions}

a) Provider: those who deliver family planning services, such as health officers, nurses or midwives.

b) Quality: Quality is a multidimensional concept but in this study quality will be measured in terms of client satisfaction, technical competence of providers and 
availability \& functionality of facilities supplies and instruments for FP service provision.

c) Client Satisfaction: This is clients' opinion of care received from FP services/ staff and is acknowledged as an outcome indicator of quality of service. In this study, percent of mean score of the satisfaction scale will be used to measure the level of client satisfaction (satisfaction score) after scale transformation.

$$
\begin{gathered}
\text { Standardized } \% \text { of maximum scale } \\
(\% \mathrm{SM})=\frac{\text { Actual score-minimum score }}{\text { Maximum score-minimum score }} * 100 \%
\end{gathered}
$$

Score above $60 \%$ will be considered as satisfied [15].

a) Provider competence or practice: executing family planning service provision according to the national/international guideline. Practice will be considered satisfactory if the provider perform all procedure per standard and unsatisfactory otherwise.

b) Client-provider interaction includes all face-to-face communication between clients and service provider.

c) Waiting Time: The time gap between the client's arrival at the SDP and the time the client received FP services. Acceptable waiting time: $\leq 30 \mathrm{~min}$, and Not acceptable waiting time: $>30$ min.

d) Logistics: - Family Planning equipments, supplies and physical set-ups like storage facilities for use by service delivery points. If all necessary and basic equipments are available and functional in $>70 \%$ of the facilities, it has said to be adequate in the Woreda, if $60-70 \%$ fairly adequate, $<60 \%$ inadequate [16].

e) IEC materials: availability of flip charts, pamphlets, samples, posters and anatomical models at the SDP.

f) Equipments: the availability of necessary instruments including sterilizer, BP apparatus, weight scale, flash light, uterine sound, speculum, scissors, teneculum, antiseptic solutions needle and syringe, examination table thermometer, disposable gloves and others at the SDP.

g) Mechanisms to encourage continuity: whether the provider told the client to return for the next appointment.

\section{Result}

\subsection{Socio-demographic Characteristics}

A total of three hundred one female clients from four FP SDPs were interviewed; making a response rate of $96 \%$. As shown in table 2: Among 301 interviewed clients, 261 $(86.7 \%)$ were from rural; the majority, 290 (96.3\%), were married and live with their husband. From the total respondents $203(67.4 \%)$ of them have discussed on the FP with husband/partner. The mean age of the respondents was $25.61+/-5.464$ SD (median age 25) years old with range between 15-44 years. One hundred two (33.9\%) of the respondents belonged to the age group 25-29; from 270 women who have child, $145(48.2 \%)$ have three and above children. $206(68.4 \%)$ mothers were breast feeding; 211 (70.1\%) were illiterate. Regarding the occupational status of the respondents, 157 (52.2\%) were not working in job which pays in cash or kind in the past six month; that means they were housewives; 271 (90.4\%) were Muslim; 296 (98.3\%) were Oromo in ethnicity.

\subsection{Waiting Time}

The mean and SD of waiting time clients before getting service was $30.57+22.632$ minutes with range of $0-180$ minutes. In general, waiting time was acceptable (within 30 minute) to $214(71.1 \%)$ of the clients.

\subsection{Client-Provider Interaction During Service Provision}

In $32(65.3 \%)$ of the cases the provider greeted the clients during begging of consultations. In $25(62.5 \%)$ of observed interaction the provider informed the clients about modern family planning methods. Twenty three $(57.5 \%)$ of the clients had shown preferences to particular method. During consultation provider talk about Norplant in 21 (52.5\%), Injectable $19(47.5 \%)$, the least was condom $2(5 \%)$ and spermicidal $1(2.5 \%)$ respectively and never mention about natural method and diaphragm [Figure 2].

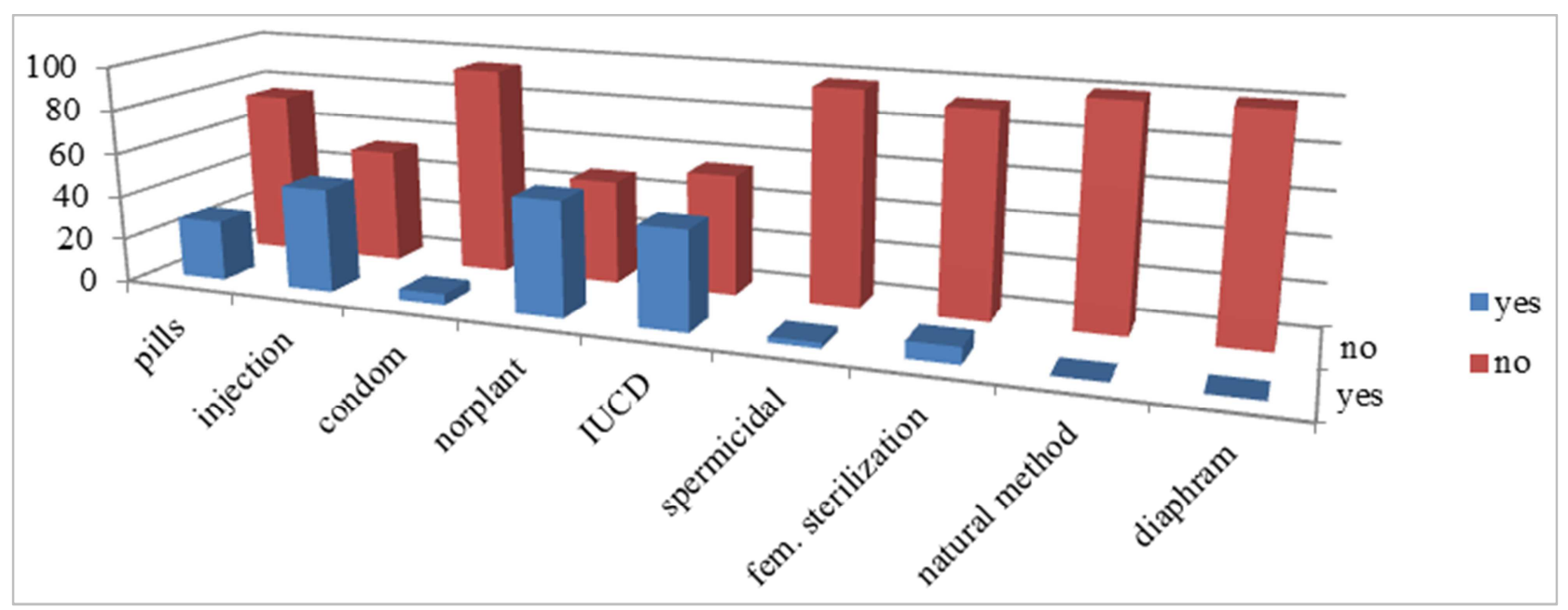

Figure 2. Methods discussed by provider Kersa Woreda public health centers, Jimma zone, southwest Ethiopia, May 2016. 
Table 2. Socio-demographic characteristics of FP clients in Kersa woreda public health centers, Jimma zone, Southwest Ethiopia, May 2016.

\begin{tabular}{|c|c|c|c|}
\hline Characteristics & Category & Frequency $(n=301)$ & Percent (\%) \\
\hline \multirow{7}{*}{ Age (in years) } & $15-19$ & 31 & 10.3 \\
\hline & $20-24$ & 88 & 29.2 \\
\hline & $25-29$ & 102 & 33.9 \\
\hline & $30-34$ & 50 & 16.6 \\
\hline & $35-39$ & 25 & 8.3 \\
\hline & $\geq 40$ & 5 & 1.7 \\
\hline & Mean age $=25.61+/-5.464 \mathrm{SD} \min =15 \max =45$ & & \\
\hline \multirow{2}{*}{ Residence } & rural & 261 & 86.7 \\
\hline & urban & 40 & 13.3 \\
\hline \multirow{2}{*}{ Marital status } & Married and live together & 290 & 96.3 \\
\hline & Others* & 11 & 3.7 \\
\hline \multicolumn{4}{|c|}{ If married /have regular partner, have you discussed family planning? } \\
\hline Yes & & 203 & 67.4 \\
\hline No & & 95 & 31.6 \\
\hline \multirow{4}{*}{ Number of living children } & No child & 31 & 10.3 \\
\hline & One & 46 & 15.3 \\
\hline & Two & 79 & 26.2 \\
\hline & Three and above & 145 & 48.2 \\
\hline \multirow{4}{*}{ Would you like to have more children } & Yes & 210 & 69.8 \\
\hline & No & 76 & 25.3 \\
\hline & Depend on God & 12 & 4 \\
\hline & Depend on husband & 3 & 1 \\
\hline \multirow{2}{*}{ Currently breastfeeding } & Yes & 206 & 68.4 \\
\hline & No & 95 & 31.6 \\
\hline \multirow{4}{*}{ Educational level } & Can't read and write & 211 & 70.1 \\
\hline & Write and read only & 36 & 12 \\
\hline & Primary school (1-8) & 44 & 14.6 \\
\hline & Secondary school completed $\&$ above & 10 & 3.4 \\
\hline \multirow{2}{*}{ Ethnicity } & Oromo & 296 & 98.3 \\
\hline & Others** & 5 & 1.6 \\
\hline \multirow{3}{*}{ Religion } & Orthodox & 17 & 5.6 \\
\hline & Muslim & 272 & 90.4 \\
\hline & Protestant & 12 & 4 \\
\hline \multirow{4}{*}{ Occupation } & Not emloyed (housewife) & 157 & 52.2 \\
\hline & Farmer & 83 & 27.6 \\
\hline & Merchant & 49 & 16.3 \\
\hline & Others $* * *$ & 12 & 4 \\
\hline \multirow{3}{*}{ Percentile per capita monthly income } & lower & 100 & 33.2 \\
\hline & middle & 101 & 33.6 \\
\hline & higher & 100 & 33.2 \\
\hline
\end{tabular}

* Others include (single, divorced, and widowed).

** Others (Amhara, Yem).

*** Others (Government employed, private employed, armed forces, daily laborer).

The provider emphasized particular method during consultation in $34(85 \%)$ of the cases. Among the methods emphasized: Norplant $12(32.5 \%)$, IUCD $12(30 \%)$, the least was pills; only $3(7.5 \%)$ cases [Figure 3 ].

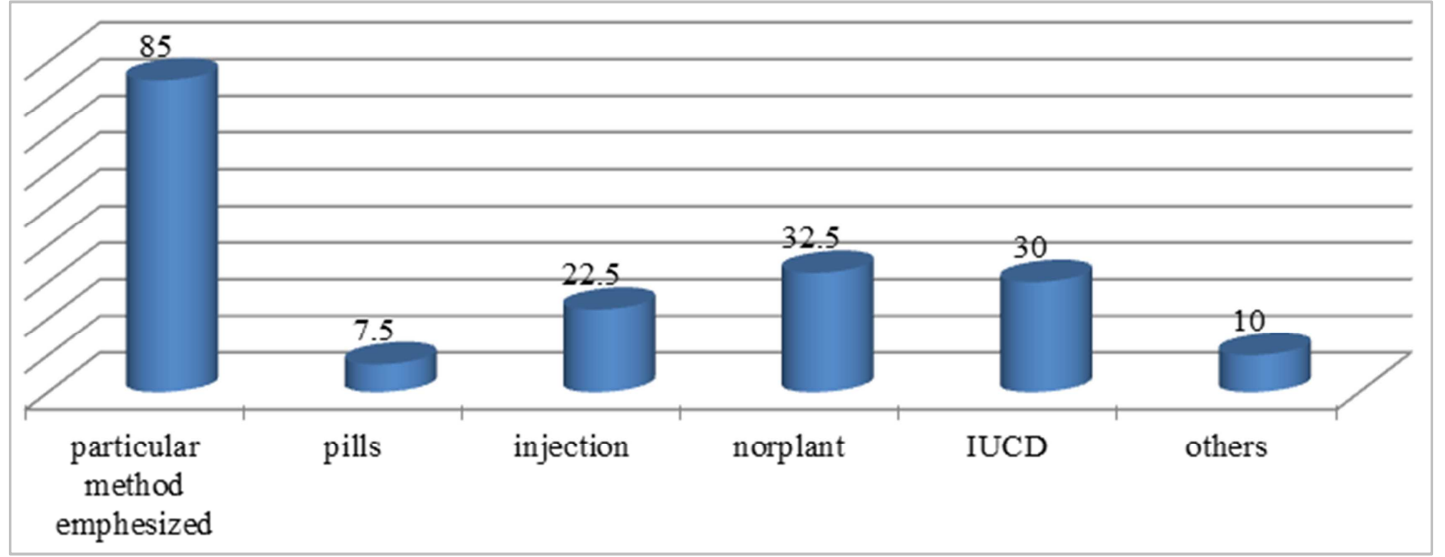

Figure 3. Particular methods emphasized during consultation Kersa Woreda public health centers, Jimma Zone, southwest Ethiopia, May 2016. 
For method selected the provider told information about how to use $16(40 \%)$, advantage $25(62.5 \%)$, disadvantage 13 (32.5\%), Side effect $25(62.5 \%)$, possibility of switching 18 (45\%), what to do if problem arise and where to for re-supply in $15(37.5 \%)$, communicated about method $13(32.5 \%)$, when to return and the provider give for the client some form of written remind $33(82.5 \%), 31(77.5 \%)$ respectively of cases. Other health issues were discussed during providerclient interaction in $14(35 \%)$ cases and the issues discussed were about Abortion 3 (7.5\%), STSs 12 (30\%), Hypertension 8 (20\%), Diabetes and Goiter 1 (2.5\%) [Table 3].

Table 3. Information provision to the clients on selected methods among all users, Kersa Woreda public health centers, Jimma zone, Southwest Ethiopia, May 2016.

\begin{tabular}{|c|c|c|}
\hline For the method selected did the provider told about the following $? \mathrm{~N}=40$ & Yes $(\%)$ & No $(\%)$ \\
\hline How to use method & $16(40)$ & $24(60)$ \\
\hline Advantage & $25(62.5)$ & $15(37.5)$ \\
\hline Disadvantage & $13(32.5)$ & $27(67.5)$ \\
\hline Side effects & $25(62.5)$ & $15(37.5)$ \\
\hline Possibility of switching & $18(45)$ & $22(55)$ \\
\hline What to do if problem arises about method & $15(37.5)$ & $25(62.5)$ \\
\hline Where to go for re-supply & $15(37.5)$ & $25(62.5)$ \\
\hline Communicated about the method & $13(32.5)$ & $27(67.5)$ \\
\hline Was the client told when to return for re-supply? & $33(82.5)$ & $7(17.5)$ \\
\hline did the provider give to the client some form of written remind & $31(93.9)$ & $2(6.1)$ \\
\hline
\end{tabular}

IEC materials utilized during consultation in $26(65 \%)$ of which flip chart $16(40 \%)$, brochure/pamphlets 15 (37.5\%) and sample of contraceptive $10(25 \%)$ [Figure 4 ].

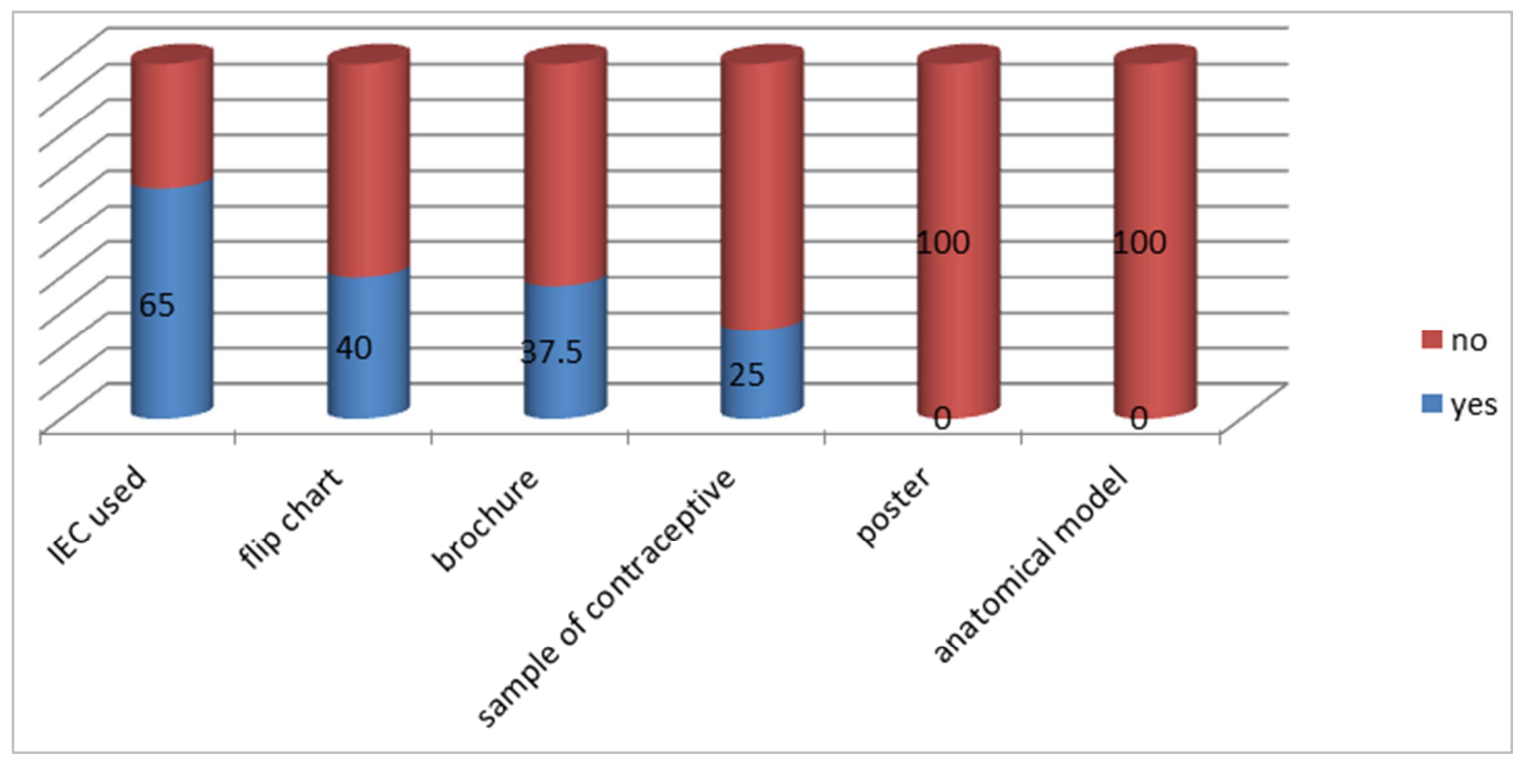

Figure 4. IEC materials used during consultation Kersa Woreda public health centers, May 2016.

\subsection{Technical Competency of the Providers}

Observation of FP service provisions was conducted to assess providers' adherence to accepted standards of quality and service delivery. Out of 301 study subjects, 40 clients were observed while receiving the service from four SDPs at different time intervals like morning, mid-day, afternoon and on market day, holiday and weekend time in four health centers total of ten cases per HC. Of the 4 observed providers, $3(75 \%)$ were female and one male diploma nurses. The mean consultation time was $12.97 \pm$ SD 9.189 with minimum and maximum values of 3 and 35 respectively. Providers performed the following procedures and activities while taking medical history, asking clients about their contraceptive method history in $17(42.5 \%)$, date of last menstrual period $28(70 \%)$, pelvic pain $6(15 \%)$, take weight $6(15 \%)$, check blood pressure $10(25 \%)$, STIs $8(20 \%)$, unusual vaginal discharge/bleeding $12(30 \%)$ of the clients. Providers performed a physical examination on $8(20 \%)$ of the clients and sent laboratory request to confirm problems in only $1(2.5 \%)$ of the cases. Averagely in the case of 13 $(33.3 \%)$ providers took adequate reproductive history, but in the case of $66.7 \%$ complete history was not taken [Table 4 ]. 
Table 4. Medical history and physical examination during client provider interaction in Kersa woreda public health centers, Jimma zone, Southwest Ethiopia, May 2016.

\begin{tabular}{lll}
\hline \multirow{2}{*}{ Medical history and physical exam $(\mathbf{N}=\mathbf{4 0})$} & Yes & No \\
\cline { 2 - 3 } & $\mathbf{N}(\mathbf{\%})$ & $\mathbf{N}(\mathbf{\%})$ \\
\hline Does client informed about modern family planning? & $25(62.5)$ & $15(37.5)$ \\
Provider ask About contraceptive method history & $17(42.5)$ & $23(57.5)$ \\
About date of LMP & $28(70)$ & $12(30)$ \\
Unusual vaginal discharge/bleeding & $12(30)$ & $28(70)$ \\
Pelvic pain & $6(15)$ & $34(85)$ \\
Take weight & $6(15)$ & $34(85)$ \\
Take blood pressure & $10(25)$ & $30(75)$ \\
Sexual Transmitted disease Problems symptoms & $8(20)$ & $32(80)$ \\
Perform Physical examination & $8(20)$ & $32(80)$ \\
Did laboratory test & $1(2.5)$ & $39(97.5)$ \\
\hline
\end{tabular}

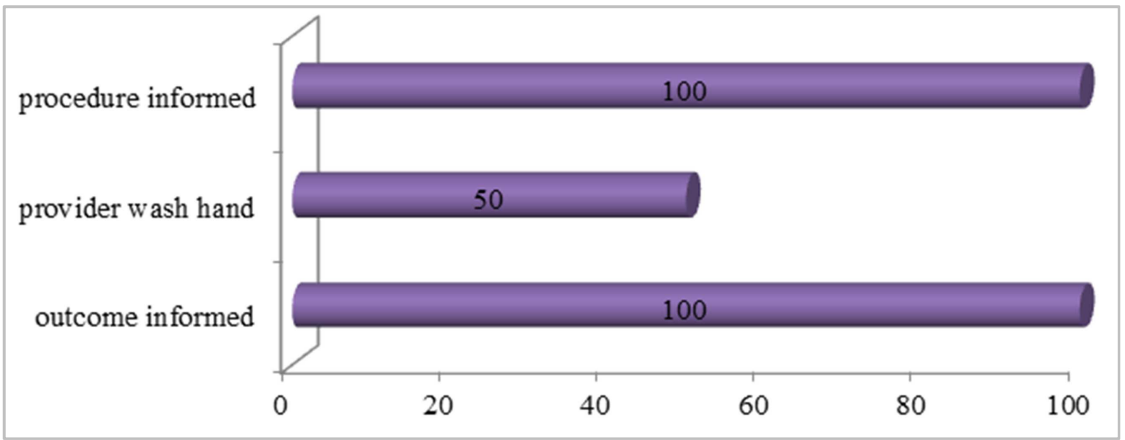

Figure 5. Procedures during pelvic examination in Kersa Woreda public health centers, Jimma zone, Southwest Ethiopia, May 2016.

For four clients a pelvic examination was made, among them sterile techniques were maintained and the outcome was informed for all (100\%) service users but providers washed hands before and after the procedures in $2(50 \%)$ of the cases. Averagely about $30.25 \%$ of the clients had been examined by the providers appropriately but the rest $69.75 \%$ were not examined. On in-depth interview also the providers mentioned lack of water and washing facility in all $\mathrm{HC}$ [Figure 5].
Among 20 Injectable users, in all cases providers selected an appropriate injection site and used new or sterile needles and syringes and DAMP (Deoxy medroxy progesteron acetate) vials were well shaken before drawing in to the syringes but disinfected the injection site for 17 (85\%) cases. In the case of all clients, providers did not massaged injection site after giving DAMP injection. All clients received their injections by service providers in the same room [Table 5].

Table 5. Technical activities during injection provision in Kersa woreda public health centers, Jimma zone, Southwest Ethiopia, May 2016.

\begin{tabular}{llll}
\hline \multirow{2}{*}{ Questions } & Responses & \multicolumn{1}{c}{ Yes (\%) } \\
\cline { 2 - 4 } & & Yes (N) & 100 \\
& If Injectable was given to the client, did the provider do the following & 20 & 100 \\
if injection was given & New or sterile needle and syringe used? & 20 & 17 \\
& Injection site disinfected? & 20 & 85 \\
& DEPO vial shaken before drawing in to Syringe? & 20 & 100 \\
& Clint took injection? & 100 & \\
\hline
\end{tabular}

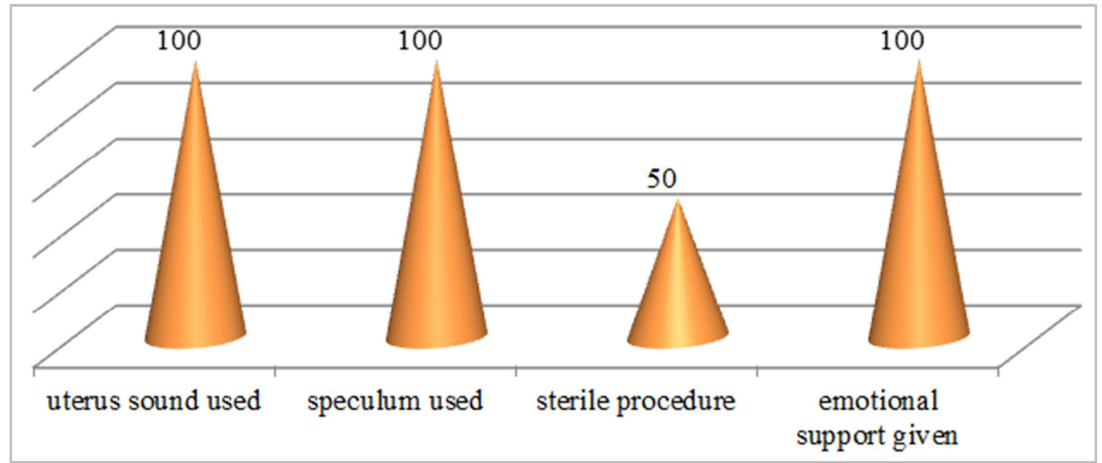

Figure 6. Technical activities while inserting IUCD in Kersa Woreda public health centers, Jimma zone, Southwest Ethiopia, May 2016. 
For four IUCD users, in all the case uterus sound, a speculum was used and an emotional support was given but for only two of clients sterile procedures maintained [Figure $6]$.

Some of the technical quality indicators were assessed using in-depth interview with service providers. One service provider from each SDP (3 females and 1 male) was interviewed. Out of the four service providers, all of them were diploma nurses. The average service years of providers while offering all types of services were 3.75 whereas only 2.625 years while offering family planning services. Providers from 3 health centers, except Kellecha HC received training on basic family planning services.

Providers mentioned the need for training as the 'one thing' that would help to improve quality.

One of the provider's from one of the health centers said that "...although it is obvious that having training on basic or specific family planning methods is very important specially long acting family planning methods for the provision of quality services, still we have not been given any in-service training either from the government or nongovernmental organizations. Because of this, we are unable to provide all F/P methods per clients need...."

Another provider from other HC also said that "...actually we have received $\mathrm{MCH}$ (maternal and child health) course while we were at college which was mainly dealt about $\mathrm{MCH}$ including FP. Besides attending the class, having trainings, specifically method related practical trainings, are important for improvement of the quality service delivery process. ..."

The entire service providers mentioned the importance of availability of different contraceptive methods as if different methods were available at the SDPs, clients may get their method of choice. For example in case if the method which was selected by the client might be medically contraindicated so in this case the availability of other methods is important to satisfy the needs of clients.

In addition, if a client may request a method which was not available in your facility what you will do?" all the providers responded that after giving counseling they would refer the client to the nearest facility where the required services are available.

For the question: "Is there a method to follow up defaulters among family planning clients? ", providers from all health centers answered they will get the clients if they come again then advise to continue the method on voluntary basis if they are not already pregnant. Concerning problems, which are beyond their capacity to deal with, all replied for the referral of clients to higher health institutions. All providers were asked about the existing problems that hinder them in the service delivery process. Lack of basic training, shortage of supplies especially Injectable and lack of infection prevention facilities were among the list.

\subsection{Availability and Functionality of Logistic Supplies and Facilities}

The official opening hours for all of the selected health centers from Monday to Friday were 8:30 am to 5:30 pm with exception of lunch time (12:30 am-1:30 pm from Monday to Thursday and 11:30 am-1:30 pm on Friday). All the SDPs start service delivery soon after the official opening except one of the HC (Serbo HC) which starts service delivery on 9:30 am and 2:00 pm. All of the health centers had no sign that announce family planning services are available except a Label on the gate of each room which marks its family planning service delivery class. Two of the health centers had two staffs that provide family planning services and the other two health center had three staff that provides the services. Out of ten providers six of them had in-service training but one of the health center (Kellecha HC) had no trained provider at all. Untrained providers feel that they don't have up-to-date knowledge on long term than short term FP service provision. The providers think that practical training is important to improve FP service.

Table 6. Summary of supplies \& equipments available at different SDPs in Kersa Woreda public health centers, Jimma zone, Southwest Ethiopia, May 2016.

\begin{tabular}{lll}
\hline Type of equipments and supplies & Number (N) of SDPs available & Percent (\%) \\
\hline Sterilizer & 4 & 100 \\
BP apparatus & 4 & 100 \\
Weight Scale & 4 & 100 \\
Flash light & 0 & 0 \\
Teneculum & 4 & 100 \\
Uterine sound & 2 & 50 \\
Speculum & 4 & 100 \\
Scissors & 4 & 100 \\
Antiseptic solutions & 4 & 100 \\
Sterile or Disposable gloves & 4 & 100 \\
Examination table & 4 & 100 \\
Thermometer & 4 & 100 \\
Needle and syringe & 4 & 100 \\
Pregnancy test & 3 & 75 \\
Autoclave & 4 & 100 \\
Different contraceptive methods & & 100 \\
IUCD and Norplant & 4 & 100 \\
Pills, Injectable and Condom & 4 & \\
\hline
\end{tabular}


Regarding the availability of IEC material at the health facility, different IEC materials like flipchart, FP posters and contraceptive samples were observed in which all the health centers had sample of each materials but anatomical models were available in Serbo and Kusaye beru HCs. All of the health centers had no standard FP guideline except Serbo $\mathrm{H} / \mathrm{C}$. All of the health centers had separate room for physical examination but it's not facilitated within family planning service delivery unit in all HCs.

Concerning the availability of basic equipments (equipment and commodities), each health center had sterilizer /Autoclave, Blood pressure apparatus, Weight Scale,, Uterine sound except Kellecha HC, Speculum, Scissors, teneculum, Antiseptic solutions, Disposable gloves, Examination table, Thermometer, Needle and syringe, Sterile gloves, Pregnancy test except Serbo HC, Different contraceptive methods and Minor surgery set. Flash light is not available in all health centers.

Blood pressure apparatus, examination bed and stethoscope were shared commonly with other departments like ANC and delivery room in all health centers except Serbo HC in which there is no functional BP apparatus.

Averagely $89.7 \%$ of FP service provision supplies and

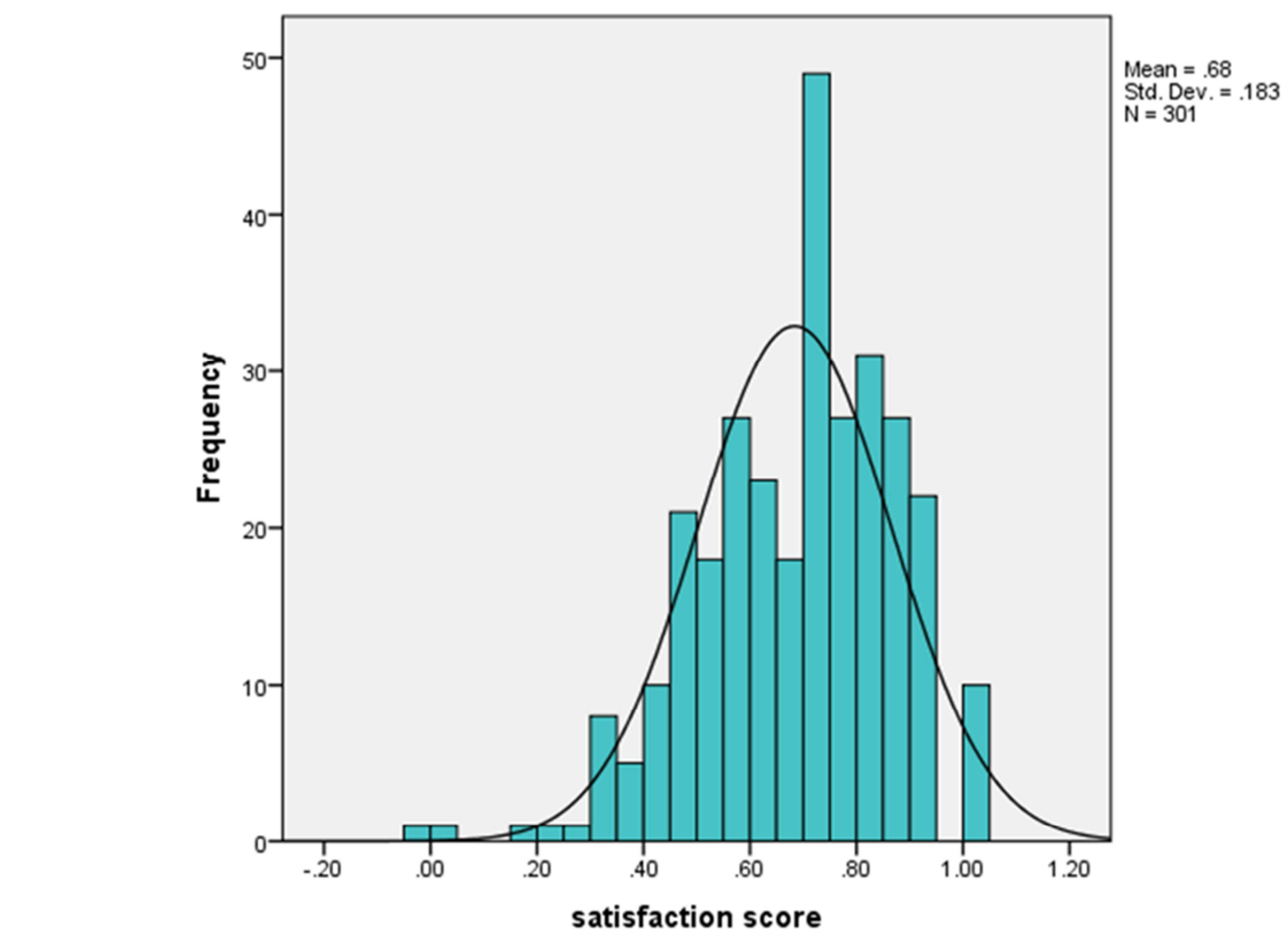

equipments are available in all observed health centers. All of the health centers had functional Bin card system for received \& dispensed FP commodities according to RRF and adequate shelf for storage facilities.

All observed health centers had functional HMIS like individual old\& new client records, daily family planning activity logbook and monthly, quarterly and annual FP activity report. Supportive supervision was conducted from higher units for all $\mathrm{HCs}$ in the past quarter except one $\mathrm{HC}$ (Kellecha HC) which had no supervision in the past quarter. No written feedback from immediate supervisor and higher unit was observed on past quarter family planning activity report and supervision [Table 6].

\subsection{Client Satisfaction with the Family Planning Service}

The overall satisfaction score which was the outcome variable was measured using computed satisfaction score to be used in the regression model. The percentage mean score of overall satisfaction is $68 \%$ with minimum 0 and maximum 100. Based on overall satisfaction score $68.8 \%$ of clients were satisfied in family planning services [Figure 7].

Figure 7. Clients family planning service satisfaction in Kersa Woreda public health centers, Jimma zone, Southwest Ethiopia, May 2016.

Specific to each satisfaction item, majority of the respondents were satisfied to ease of getting clinic site $67.1 \%$, waiting time $91.7 \%$, clinic working hour conveniences $95.4 \%$, cleanliness of clinic area $78.1 \%$, availability of sufficient methods $97.1 \%$, waiting place adequacy with latrine and water $80.4 \%$, provider performance of procedure with cleanness $99 \%$, friendliness $\&$ respectfulness of the staff treatment $98.3 \%$, sufficiency of consultation time $97.3 \%$, with sufficiency information given $98.6 \%$, maintaining privacy $98.4 \%$, coming back if need help $94.8 \%$ and recommend the service to relatives and friends $99 \%$. Whereas, about $22.6 \%, 2.3 \%$ and $1.3 \%$ of the respondents were relatively not satisfied to getting clinic site easily, not too long 
waiting time and maintaining privacy respectively [Table 7].

Table 7. Clients family planning service satisfaction in Kersa Woreda public health centers, Jimma zone, Southwest Ethiopia, May 2016.

\begin{tabular}{|c|c|c|c|c|c|}
\hline \multirow{2}{*}{ Characteristics } & \multirow{2}{*}{$\begin{array}{l}\text { Strongly Disagree } \\
\mathrm{N}(\%) \\
\end{array}$} & \multirow{2}{*}{\begin{tabular}{l|} 
Disagree \\
$\mathrm{N}(\%)$ \\
\end{tabular}} & \multirow{2}{*}{$\begin{array}{l}\text { Neutral } \\
\text { N (\%) } \\
\end{array}$} & \multirow{2}{*}{$\begin{array}{l}\text { Agree } \\
\mathrm{N}(\%) \\
\end{array}$} & \multirow{2}{*}{$\begin{array}{l}\text { Strongly agree } \\
\mathrm{N}(\%) \\
\end{array}$} \\
\hline & & & & & \\
\hline The clinic site is easy to get & $60(19.9)$ & $8(2.7)$ & $31(10.3)$ & $117(38.9)$ & $85(28.2)$ \\
\hline Waiting time was not too long & 0 & $7(2.3)$ & $12(4)$ & $179(59.5)$ & $103(34.2)$ \\
\hline Clinic hours are convenient & 0 & $2(0.7)$ & $12(4)$ & $176(58.5)$ & $111(36.9)$ \\
\hline Clinic area is clean & $1(0.3)$ & $1(0.3)$ & $64(21.3)$ & $145(48.2)$ & $90(29.9)$ \\
\hline Sufficient methods are available & 0 & $2(0.7)$ & $7(2.3)$ & $70(23.3)$ & $222(73.8)$ \\
\hline Waiting place is adequate with latrine and water supply & $1(0.3)$ & 0 & $58(19.3)$ & $174(57.8)$ & $68(22.6)$ \\
\hline Provider perform the procedure with cleanliness and sanitation & $1(0.3)$ & $1(0.3)$ & $1(0.3)$ & $88(29.2)$ & $210(69.8)$ \\
\hline Staff here are really friendly and respectful & 0 & $1(0.3)$ & $4(1.3)$ & $76(25.2)$ & $220(73.1)$ \\
\hline I have had sufficient consultation time to discuss about my needs & 0 & $2(0.7)$ & $6(2)$ & $121(40.2)$ & $172(57.1)$ \\
\hline Information given about the method is sufficient & 0 & $1(0.3)$ & $3(1)$ & $94(31.2)$ & $203(67.4)$ \\
\hline Privacy was maintained & $1(0.3)$ & $3(1)$ & $1(0.3)$ & $46(15.3)$ & $250(83.1)$ \\
\hline I would come back here if I need help again & 0 & $1(0.3)$ & $2(0.7)$ & $40(13.3)$ & $258(85.7)$ \\
\hline I would recommend the service to friends and relative & 0 & $1(0.3)$ & $71(23.6)$ & $52(17.3)$ & $177(58.8)$ \\
\hline
\end{tabular}

\subsection{Factors Predicting Client Satisfaction with the Family Planning Service}

By taking into account the client satisfaction to family planning implied as direct determinants of quality of family planning services, so that factor affecting satisfaction of FP users to FP service provision would also affect the quality of family planning services. Therefore, on multiple linear regression analysis the highly significant predictors of client satisfaction to family planning services are like to have more children, currently breast feeding, discussion of FP with husband/partner, family size. Marital status and number of living children are also significant whereas Age, Age of youngest child, educational status and occupation were not.

According to the finding of this study; for a single individual increase in family size the satisfaction score decreases on average by 0.8 at $\mathrm{p}=0.007$, CI $(0.005-0.034)$. For a unit increase in need to have more child, client satisfaction decreases by 0.947 at $p=0.002$, CI $(0.019,0.088)$ Keeping the others are in the model [Table 8].

Table 8. Factors predicting the satisfaction of clients on family planning services, Kersa Woreda Jimma zone public health center, May 2016.

\begin{tabular}{|c|c|c|c|c|c|c|}
\hline \multirow{2}{*}{ Model } & \multicolumn{2}{|c|}{ Unstandardized Coefficients } & \multirow{2}{*}{$\begin{array}{l}\text { Standardized Coefficients } \\
\beta\end{array}$} & \multirow{2}{*}{ P-value } & \multicolumn{2}{|c|}{$95 \%$ CI for $\beta$} \\
\hline & $\beta$ & Std. Error & & & LB & UB \\
\hline (Constant) & .562 & .081 & & .000 & .402 & .722 \\
\hline Age & $9.082 \mathrm{E}-005$ & .002 & .003 & .969 & -.004 & .005 \\
\hline Marital status & .067 & .028 & .139 & $.018^{*}$ & .012 & .121 \\
\hline Discussed FP with husband or partner & -.061 & .023 & -.163 & $.007 * *$ & -.106 & -.017 \\
\hline Number of living children & -.035 & .017 & -.193 & $.044 *$ & -.068 & -.001 \\
\hline Age of youngest Child in month & $3.758 \mathrm{E}-005$ & .001 & .004 & .963 & -.002 & .002 \\
\hline Currently breastfeeding & -.079 & .028 & -.201 & $.005^{* *}$ & -.134 & -.024 \\
\hline Educational level & .024 & .012 & .119 & .054 & .000 & .048 \\
\hline Occupation & -.005 & .007 & -.041 & .466 & -.018 & .008 \\
\hline Family size & .020 & .007 & .214 & $.007 * *$ & .005 & .034 \\
\hline
\end{tabular}

Note: - *significant, and **highly significant. LB-Lower bound and UB-Upper bound.

\section{Discussion}

This study identified major constraints in family planning service delivery points in Kersa Woreda Jimma zone, which was related to quality of family planning issues. Three hundred one female clients were interviewed for this study. Similar with other parts of the country, male partners do not attend FP services regularly in the Woreda and it is difficult to get the required sample size that can be representative for male clients at facilities level. Unavailability of adequate male methods might be the possible reason for the nonattendance of male partners at SDPs. The majority were married $(96.3 \%)$ in the age group of 25 to 29 , which is consistent with findings from Jimma zone [10] and North West Ethiopia [17]. The possible reason for this relative high percentage of married women could be due to regular sexual contact with their husband and fear of unwanted pregnancy and married women are not afraid of cultural influence and they can use contraceptive methods anywhere freely.

This study also revealed that there was decreased attendance of unmarried clients $2(0.7 \%)$ which is consistent with similar study done in Jimma $12(1.9 \%)$ [10] before ten years. This is one problem identified in this study. This might be due to the unimproved provider attitudes towards such clients and the unchanged attitudes of unmarried clients toward SDPs which hindered them from visiting SDPs. Majority of the clients are rural population (86.7\%), this may be due to the majority of the Woreda population around $90 \%$ are rural residents.

Most family planning users in this study can't read and 
write $(70.1 \%)$, which is higher than study in Jimma zone $42.5 \%$, and $51 \%[10,11]$. The probable reason for this might be early marriage and being housewife. Since they are caretakers for the whole families and they did not have time to attend their school. Lower educational status of clients might make them unable to ask questions and less understands information about different methods.

The mean and SD of waiting time clients before getting service was $30.57+22.632$ minutes with range of $0-180$ minutes which is almost similar with study in Jimma 31.7 minutes [10] and higher than the study in Jimma public health centers $16.4+18.1$ minutes [11] but lower than study in Bahirdar (48 $\pm 51 \mathrm{~min})$ [13]. In general, waiting time was acceptable (within 30 minute) to $214(71.1 \%)$ of the clients.

\subsection{Client Provider Interaction}

The mean consultation time was $12.97 \pm$ SD 9.189 ranging from 3 minutes to 35 minutes, which is nearly consistent with study done five years back in Jimma zone 10.5 \pm 8.3 minutes (range $=3-50$ minutes) minutes (36) and northwest Ethiopia 10.1 [17].

Greeting clients in the first contact at service delivery points enhances the interaction as it has emotional contents of exchange between provider and clients. Inconsistent with GATHER or ORPA model (Greet clients, Ask clients about themselves, Tell clients about FP methods, Help clients to choose a Method, Explain how to use method chosen, Refer or return for follow-up) or Observe, Reflect, Personalize, Act) guide of family planning provision in which providers in $100 \%$ of the cases should stick to the guideline during consultations, in this study providers greeted only $65.3 \%$ of their clients, which is similar with the study done in Jimma zone (65.3\%) [11], and lower than study done in northwest (74\%) [17].

About $62.5 \%$ of observed interaction the provider informed the clients about modern family planning this is lower than the study in Jimma (82\%) [11]. This indicates most of the family planning providers are not consistently working as per guideline which in turn compromises the quality of family planning services. This might be due to provider neglect or running behind time in case of client over flow.

The provider emphasized particular method during consultation in $34(85 \%)$ of the cases. Consistent with study in Jimma zone public health centers [11], in most of the cases providers explained about Norplant than any other contraceptive methods which might be due to the current trainings rendered on long term contraceptive methods from both government and NGOs side that might inclines the provider to long term FP like Norplant than the others. Thus it might negatively affect the success of FP service utilization in those clients who were not informed well. But in contrary to study done in Northwest and Jimma zone $[17,10]$ in which discussion about Norplant was made in $(10 \%, 11 \%)$ only. On the other hand similar to study done in North West Ethiopia; no discussions were made on female sterilization [17]. In contrary, studies from India [18] have shown that the provider emphasized sterilization alone and in $71 \%$ of these cases, the method they stressed was female sterilization. The discrepancy might be due to policy difference between the two countries. This is evidenced by all other similar studies in Ethiopia showed no considerable difference in terms of information provision.

The providers talk about condom only in 2 clients; this once again indicates that condom as a family planning method or a method of "Dual Protection" is rarely provided in heath institutions.

The discussion about the family planning method supplied to the clients also seems unsatisfactory. For example the possible side effects of the methods were discussed only with $62.5 \%$ clients, for method selected the provider told information about how to use $40 \%$, advantage $62.5 \%$, disadvantage $32.5 \%$, side effect $62.5 \%$, possibility of switching $45 \%$, what to do if problem arise and where to go for re-supply in $37.5 \%$ and communicated about method in only $32.5 \%$ of clients. Study conducted in East Show Zone, Oromia Regional State, also indicated that providers did not discuss with clients on the side effect of the specific family planning methods they took (67.7\%) [19]. This could reflect low counseling skills of service providers in problem solving. Such incapability to resolve common side effects of the method could be the factors associated with service switching or discontinuation use of family planning services completely, as revealed in the study conducted in Kenya [20].

This was the case when fear of side effects was mentioned as one of the reasons for not using contraceptives. The lack of discussion would not allow clients to understand the actual side effects (not rumors) and know the measures that could be taken to avoid or minimize these side effects and seek solutions in case of problems. Lack of such information may enhance method discontinuation and spreading of false rumors about side effects. Almost all issues are discussed in less than half of the clients but according to the national family planning guideline of Ethiopia; all clients have the right to get full information. So low coverage of discussion on method provided was one gap identified in this study. Other health issues discussed during provider-client interaction in only $35 \%$ cases and the issues discussed sexually transmitted diseases $30 \%$, which is higher than the study from Jimma 18 (2.6\%) [10].

According to study in North West Ethiopia none of the providers used IEC materials except for contraceptive samples in $22 \%$ of observation sessions during consultations [17] and $33 \%$ of FP providers used at least one IEC material during consultations. However, in the current study $65 \%$ of the family planning providers used at least one IEC material during consultations; which is almost two times higher than the previous study. This great discrepancy can be attributed to variation in the time of study, the growing emphasis given customized services and providers' experience but still lower than standard FP guideline recommendation.

\subsection{Technical Competence of the Providers}

Important indicators of technical quality of care include providers' complete and accurate knowledge of methods, 
physical examination and reproductive health care, as well as acceptable clinical practice of FP and reproductive service delivery [18]. In these the study $33.3 \%$ had providers taken complete reproductive history of the clients. Less than one third of the clients $(30.25 \%)$ were examined appropriately. As per national FP guideline providers are expected to take complete reproductive history and examine all their clients properly.

Concerning the infection prevention activities; although the providers give attention for clients using intra uterine devices (IUCD); but only in the case of $50 \%$ providers kept sterile techniques like washing hands before and after procedures. The main reason mentioned by all providers during qualitative study was that two HCs have no water in their compound and the other two who have water facility mentioned no functional sink in FP service provision class. Therefore another problem identified in this study was the providers are not executing what is expected of them and not serving per standard which is the similar; as reflected in previous work [11].

\subsection{Availability and Functionality of Logistic Supplies and Facilities}

Almost all of SDPs had IEC materials other than anatomical models, which is higher than a study done in Dale Woreda and Colombia (48\%) [16, 21]. But during observation, most of them were not utilized by service providers. The probable reason for not utilizing them might be work over load, since staffs having working in both FP service and other outpatient activities which creates shortage of staffs in Serbo HC for it have high client load. Another reason might be that most providers do not understand the importance of IEC materials or they under estimate the importance of them. This is consistent with study done in Dale Woreda and Colombo [16, 21].

Eighty nine percent $(89.7 \%)$ of basic equipments and supplies for FP service delivery were available in all audited SDPs which was adequate and higher than study done in Dale Woreda in which only two thirds $(66.7 \%)$ of the SDPs have all basic and necessary equipments and supplies. The Ethiopian ministry of health $(\mathrm{MOH})$ guidelines of FP services was to be used at all levels of SDPs, however in this study, it was found that only 1 (25\%) of SDPs have national and international FP guidelines which is consistent with study in Dale Woreda [16] but higher than study in Jimma public health centers [11] in which all SDPs had no guidelines of FP services and lower than study in Jimma $(37.5 \%)$ [10]. It is obvious that in the absence of the guideline, implementation of the stated objectives and principles for the betterment of quality would be difficult. As recommended in the guideline of FP services in Ethiopia; a minimum of 4 trained FP service providers are required per Health center. Despite this two of the four health centers in this study had only 2 trained FP service providers which were similar to what was reported by earlier workers $[22,17,11$, 23].

The health facilities were functional throughout the working days 8 hours per day staring from Monday to Friday in the week. Three $(75 \%)$ of the HCs start service delivery as patient arrive without delay which is better than the study in Jimma public HCs 33 minute after official opening hour [11]. But in contrary to other SDPs; in Serbo HC service delivery process begun around 1hour in the morning and 30 minutes in the afternoon after official opening. These delays were due to time taken to pass health information but it might dissatisfy those clients who come early in the morning which is similar to previous study [11].

\subsection{Client Satisfaction}

The percentage mean satisfaction score of overall satisfaction was $68 \%$ and sixty eight percent $(68.8 \%)$ of clients were satisfied in family planning services. This is lower than the study in Jimma public health centers $93.7 \%$ [11] and Sirilanka, Colombo district $80.8 \%$ [21] but higher than satisfaction report from Iran $61.3 \%$ [24]. The probable reasons for the discrepancy between the two studies might be due to increased awareness and expectation of client's in due course for study in Jimma and socio demographic differences between the two study populations for study in Sirilanka.

On multiple linear regression analysis the highly significant predictors of client satisfaction to family planning services are like to have more children, currently breast feeding, discussion of FP with husband or partner, family size. Marital status and number of living children are also significant; whereas Client Age, Age of youngest child, Educational status, Occupation and other socio-demographic variables of the clients were not. Study done in Jimma public HCs [11] also shows that other socio demographic variables like age, occupation and the like are not significant predictors except educational status which is significant predictor. The finding of this study was inconsistent with study in Guji Zone and Iran in which age of the clients were significantly associated with satisfaction [25].

\subsection{Strengths and Limitations of the Study}

\subsubsection{Strengths}

a) Different data collection methods utilized in the study and triangulation was used which could increase the validity of the study.

b) Structured, previously used and valid questionnaire and check lists were used.

\subsubsection{Limitations}

a) A major limitation of the study was the selectivity problem. For the study considers women returning to the clinic, the satisfaction scores may be biased upward since women that may have not been happy with the service may not come to the SDPs.

b) Providers might also show their best behavior responses during the client-provider interaction (observation bias) and perhaps clients might also show courtesy bias during the exit interview.

c) Although the study utilized previously tested tools; the model can describe only $15 \%$ of the outcome variable. 


\section{Conclusions and Recommendations}

\subsection{Conclusions}

This study revealed several constraints in the provision of FP services with improved quality of care, which can be implied as area of possible improvement.

a) There was decreased attendance of unmarried clients $(0.7 \%)$

b) Waiting time before getting the service was acceptable for $71.1 \%$ of the clients

c) Utilization of IEC material during consultations was low $(65 \%)$

d) Providers didn't assessed critical information's in more than two third of observed sessions of history taking and physical examinations.

e) Most of the family planning providers are not consistently working as per guideline

f) The provider emphasized particular method during consultation in $(85 \%)$ of the cases.

g) The information about the family planning method supplied to the clients like how to use, advantage, disadvantage, side effects seems unsatisfactory.

h) No mechanisms were set to trace FP service defaulters.

i) About $89.7 \%$ of basic equipments and supplies for $\mathrm{F} / \mathrm{P}$ service delivery are available in all audited SDPs.

j) The numbers of trained staffs in the facilities are not adequate as per $\mathrm{MOH}$ family planning guideline.

k) Shortage of adequate water supply

1) Lack of regular supervisory visit by higher unit and absence of written feedback

m)Absence of copy of MOH guideline of FP services in Ethiopia would make the implementation of the stated objectives and principles difficult for the improvement of quality of care in family planning services.

n) About $68.8 \%$ of FP clients in this study were found to be satisfied by the quality of the FP service they received.

o) The highly significant predictors of client satisfaction to family planning services were like to have more children, currently breast feeding, discussion of FP with husband/partner and family size.

\subsection{Recommendations}

Based on the Above Findings, the Following Recommendations are given

a) The Woreda health office and all respective health centers should create conducive environment for single or unmarried clients.

b) National and WHO family planning guidelines should be distributed to all health facilities by Kersa Woreda health department.

c) Service providers should be sensitized and motivated to give complete information on a method to the client.

d) The way Family planning providers comply with guideline recommendations and utilize IEC materials consistently during client consultations need to be designed by respective health centers

e) A follow up system is necessary for retaining clients, instead of concentrating exclusively on recruiting new ones.

f) Woreda health office and other higher program supporters should provide appropriate feedbacks especially during supervision and after receiving reports

g) Woreda health office should facilitate need based inservice training for adequate number of family planning providers.

h) Infrastructures, especially provision of permanent washing facilities and maintaining sinks is very essential and each $\mathrm{HC}$ should correct it as soon as possible.

i) Finally study that addresses issues not addressed in this work is recommended for interested researchers.

\section{Lists of Abbreviation}

a) $\mathrm{CI}$ : Confidence Interval

b) CPR: Contraceptive Prevalence Rate

c) DHS: Demographic and Health Survey

d) FP: Family Planning

e) HC: Health Center

f) HMIS: Health Management Information System

g) ICPD: International Conference on Population and Development

h) IEC: Information, Education and Communication

i) IRB: Institutional Review Board

j) IUDs: Intra Uterine Devices

k) $\mathrm{MOH}$ : Ministry of Health

1) NGO: Non Governmental Organization

m)OCP: Oral Contraceptive Pill

n) PHCU: Primary Health Care Unit

o) SDP: Service Delivery Point

p) SPSS: Statistical Package for Social Studies

\section{Ethics Approval and Informed Consent}

Before the fieldwork, ethical clearance was obtained from Institutional Review Board (IRB), Jimma University College of public health and medical sciences. Then formal letter of cooperation was written from Jimma zonal health office to Kersa Woreda health office and then to each service delivery points. Response of clients was anonymous and data collectors have informed clients that they have full right to discontinue or refuse to participate in the study. A letter of agreement was also attached to questionnaire to obtain the permission of each individual. Then observers have obtained permission from both providers and clients to be present during individual counseling and clinical examination.

\section{Data Availability}

The finding of this study is generated from the data collected and analyzed based on stated methods and materials. The original data supporting this finding are available from 
the corresponding author on reasonable request.

\section{Competing Interests}

The authors declare that they have no competing interests.

\section{Authors' Contributions}

$T J$ participated in the design of the study, performed the data collection and the statistical analysis and served as the corresponding author of the manuscript. EA and $Z K$ supervised the study, ensured quality of the data, assisted in the analysis and interpretation of the data. All authors read and approved the manuscript.

\section{Authors' Information}

1) Tarekegn Jabara is Quality Assurance Advisor at MIS Ethiopia West Area Program Office, Ambo town, Ethiopia

2) Elias Ali is Lecturer at Jimma University Health Science Institute, Jimma Town, Ethiopia.

3) Zalalem Kaba is Water, Sanitation, Hygiene (WASH) and Neglected Tropical Diseases (NTDs) Program Coordinator, Nekemte town, Western Ethiopia.

\section{Acknowledgements}

We are grateful to Jimma University post graduate libray and department of health service management staffs for their cooperation during the study. Our deepest gratitude also goes to all data collectors and supervisors without their hard work this work had not been successful. Last but not least our thanks go to all study participants, Jimma Zonal health department and Kersa Woreda health office administrators and staff for providing us the valuable information and support.

\section{References}

[1] Scott A, Glasier A. Evidence based contraceptive choices, Best Practice Research Clinical Obstetrics \& Gynecology. 2006; $20 \quad$ (5): $\quad 665-680 . \quad$ PMid: 16707277 http://dx.doi.org/10.1016/j.bpobgyn.2006.03.002, accessed date November 17, 2015.

[2] Basavanthappa BT. Community Health Nursing. 2nd edition. Jaypee Publishers. New Delhi: 2008. 561-562. http://dx.doi.org/10.5005/jp/books/10159, accessed date November 10, 2015.

[3] Mona Sharan, Saifuddin Ahmed, John May, and Agnes Soucat. Family Planning Trends in Sub-Saharan Africa: Progress, Prospects, and Lessons Learned), accessed date November 22, 2015.

[4] Kamell R, Wassif S. Population Problem In Egypt As One of The Priority Health Problems In Tropical Areas. Zagazig Journal of Occupation Health and Safety. 2008; 1 (2): 87.
[5] ICPD Goals: Essential to the Millennium Development Goals Marianne Haslegrave and Stan Bernstein Page 106 of 106108).

[6] Mini Ethiopian Demographic Health Survey, 2014.

[7] Saumya R., and Raji M.: The Quality of Family Planning Programs: Concepts, Measurements, Interventions, and effects, 2003.

[8] Bongaarts J: poverty, gender, and youth: Fertility Transitions in Developing Countries: Progress or Stagnation? Working paper (7), 2008.

[9] Jimma zone Health Department five years HMIS report (2002-2007 E. C), Unpublished.

[10] Loha. E, Asefa M, J. Chali, T. Fasil. Assessment of quality of care in F/P service in Jima Zone: 2003. Ethiop. J. Health Dev. 2003; 18 (1): 8-18.

[11] Tafese, F.; Woldie, M.; Megerssa, B.: Quality of Family Planning Services. Ethiop. J. Health Sci. 201323 (3): 245-254.

[12] Kersa woreda health office third quarter activity achievement report of 2008 EC.

[13] Tseganeh W: Assessment of quality of family planning Service, Bahar-dar special zone, Amhara regional state, May 2005 .

[14] Quick Investigation of Quality (QIQ): A User's Guide for Monitoring Quality of Care in Family Planning; MEASURE Evaluation Manual Series, No. 2 February 2001.

[15] Elsayda H N., Hanan E H.: Association between quality of family planning services and client's satisfaction level in maternal and child health centers in Port Said city, 2015. http://dx.doi.org/10.5430/jnep.v6n1p85.

[16] Kondale, M.: Quality of family planning services from clients' perspectives in the health facilities of dale woreda, sidama zone, south Ethiopia.

[17] Fantahun M. Quality of family planning services in Northwest Ethiopia. Ethiopia. J. Health Dev. 2005; 19 (3): 195-20.

[18] Michaela. Koening, GillianH. C. Foo, and Ketan Joshi. Quality of care within the India family planning welfare program: a review of recent evidence. Studies in family planning 2000; 31 [1]: 1-18.

[19] Mitike G. quality of Family Planning Service in the Health Facilities of East Shoa Zone, Oromia Regional State, Ethiopia 2008.

[20] Ministry of Health, Division of Family Health, Population Council, Africa Operations Research and Technical Assistance Project, 1995; (3): 16. USAID Contract No. ccp3030-c-00-3008-0.

[21] Umanga D. Silva and Pushpa Fonseka. Quality of care in government family planning clinic services in Colombo District. Ceylon Medical J. December 2008. Vol. 53, No. 4, 121-27.

[22] Asfaw Y. Assessment of quality of care in family planning service in AA, 1995).

[23] Frameworks for improving quality of services have common features, including a client emphasis. Network: Fall 1998, Vol. 19, No. 1. 
[24] Masoumeh Simbar, Mahboobeh Ahmadi, Golnoosh Ahmadi, Hamid Reza and Alavi Majd. Quality assessment of family planning services in urban health centers of Shahid Beheshti Medical Science University Iran. International Journal of Health Care Quality Assurance. 2006, Volume. 19, No. 5.
[25] Semu, Y. Clients' satisfaction with family planning service in Guji zone, oromia regional state, Ethiopia, 2014. 